\title{
Comparison and analysis of sequences and structures of hemagglutinins from Influenza $A$ Virus: a minireview
}

\author{
Dawid Nidzworski \\ Institute of Biotechnology and Molecular Medicine, Trzy Lipy 3, 80-172 Gdańsk, Poland \\ Corresponding author: dawid@ibmm.pl \\ DOI: $10.31708 /$ v1.i1.Nd2018
}

Keywords: Influenza, Hemagglutinins, Interaction

\begin{abstract}
Influenza is one of the most widespread diseases in the world. The interest in Avian Influenza Virus has been increasing through the last decade because of greater than ever possibility of a pandemic outbreak. Influenza virus belongs to the Orthomyxoviridae family, which is characterized by a high variety of hemagglutinin and neuraminidase in different subtypes. Hemagglutinin has two very important sites on its surface: receptor binding site and cleavage site. In this study, we compare the sequences and structures of various hemagglutinins. Emphasis was put on potential sites of mutations in functionally important domains. The possibility of adaptation of different types of the influenza virus to become a pandemic strain was also evaluated. More than 50 different hemagglutinins subtypes were analyzed and compared, pointing out changes in two aforementioned essential sites. In conclusion, H9 hemagglutinin has a high potential to become a Highly Pathogenic Avian Influenza (HPAl) strain. However, H13 should also be observed because it possesses features which could result in an increase of pathogenicity.
\end{abstract}

\section{Introduction}

The influenza A virus belongs to the Orthomyxoviridae, and it is one of the most frequently encountered pathogens. It infects millions of people and animals (especially birds) each year. The viruses developed a spherical or filamentary shape with the single-stranded RNA as genetic material. This feature contributes to the genetic changeability of the virus, via point mutations (antigenic drift) and reassortment (antigenic shift). The influenza virus causes millions of illness cases and thousands of deaths due to post-influenza complications. In the last 250 years, there were from 10 to 20 epidemic and pandemic outbreaks among humans. The three largest ones which caused most losses happened in the past century. In 1918, H1N1 serotype virus caused the most tragic, so-called Spanish flu epidemic, whose death toll was up to 100 million, while 200 million were affected (de Jong \& Hien, 2006; Webster, 2002). 25 years later, in the years 1957-58, the H2N2 virus caused another epidemic in Asia and killed another million people. The analysis of this strain showed it acquired high pathogenicity due to human virus $(\mathrm{H} 1 \mathrm{~N} 1)$ reassortment with the $\mathrm{PB} 1, \mathrm{HA}$ and $\mathrm{NA}$ segments of the avian virus (H5N1) and ousted the H1N1 virus strain (de Jong \& Hien, 2006). The last pandemic was 40 years ago in Hong-Kong, in years 1968-69, during which over a million people died. This $\mathrm{H} 3 \mathrm{~N} 2$ virus came into existence through reassortment of PB1 and HA segments and was another example of virus adaptation (de Jong \& Hien, 2006; Webster, 2002).

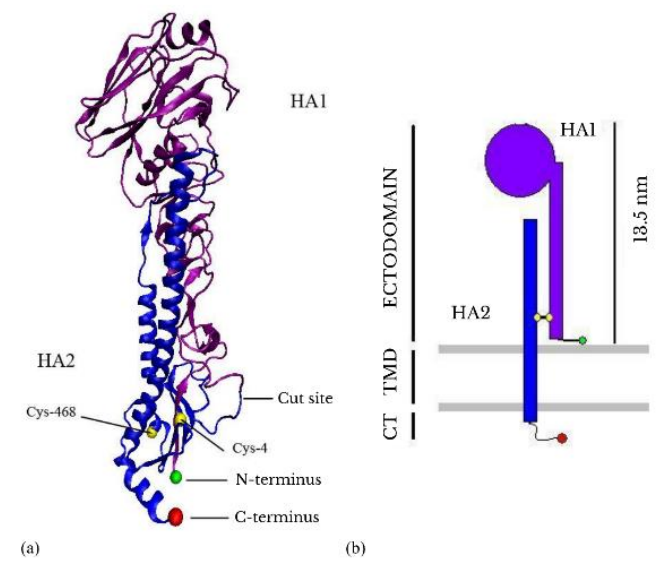

Figure 1. HAO Haemagglutinins precursor monomer; (a) crystallographic structure (PDB: 1ha0); (b) topological diagram.

Interestingly, in 1977 in Russia, the H1N1 virus reappeared although it had not been encountered for 
early 30 years possibly due to its bad maintenance in the laboratory. Since then, the infections with both H3N2 and $\mathrm{H} 1 \mathrm{~N} 1$ have been observed in the human population (Webster, 2002). Nearly 30 years after the last pandemic, the influenza virus became noticeable again, as a highly pathogenic H3N1 strain (discovered in HongKong in 1997) reappeared. This virus infected thousands of birds and also a young boy with acute symptoms in the respiratory system, leading to his death (Subbarao et al., 1998).

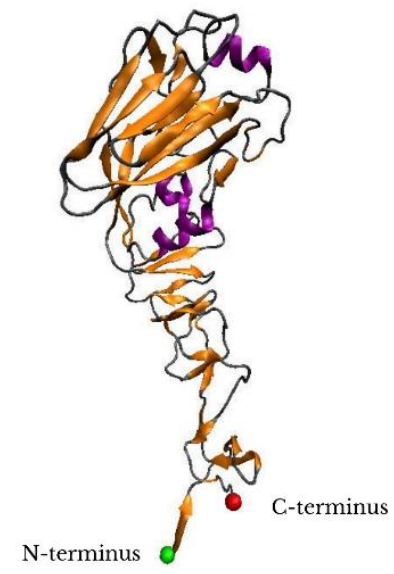

Figure 2. The HA1 subunits: The $\alpha$-helix structures have been marked in purple, while the $\beta$-sheets in orange and the $\mathrm{N}$-terminus in green and $\mathrm{C}$-terminus in red (PDB: 1ti8).

\section{Hemagglutinin - structure, and characteristics}

\section{Monomer structure}

Hemagglutinin (HA, $75 \mathrm{kDa}$, with 560 amino acid residues) is a Type I transmembrane protein, one of two glycoprotein surface antigens from influenza $A$ virus and it constitutes around $80 \%$ of all coat proteins (Nayak, Hui, \& Barman, 2004). The remaining $20 \%$ are mainly neuraminidase and over ten ion channels, created by the M2 protein. A hemagglutinin monomer primarily comes into existence in the inactive HAO form (Figure 1). Then, due to specific cutting by hosts protease, two HA1 and HA2 subunits are formed. The precursor's Cterminus is located in the virus's capsid, while the $\mathrm{N}$ terminus is on the external side, close to the lipid coat/envelope. The separated HA1 and HA2 fragments are connected by a Cys ${ }^{4}-$ Cys $^{468}$ disulfide bridge (Figure 15 - cysteines have been marked in yellow) (Kováčová, Ruttkay-Nedecký, Haverlík, \& Janeček, 2002). The monomer has a long, $\mathrm{N}$-terminal ectodomain (348 aa), a transmembrane domain (TMD, 200 aa) and a short cytoplasmic tail (CT - $11 \mathrm{aa})$. The HA1 subunit consists of 328 amino acid residues $(55 \mathrm{kDa})$ and is

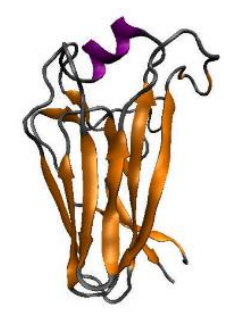

(a)

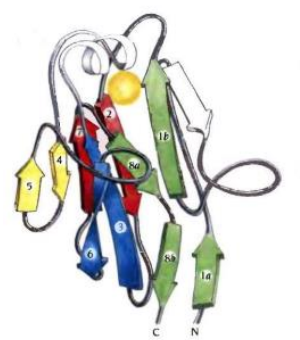

(c)

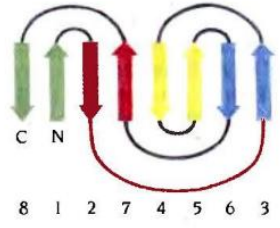

(b)

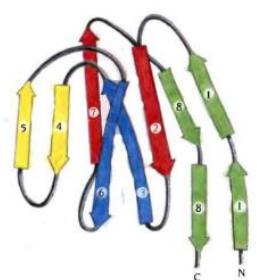

Figure 3. The "jelly roll" element in the HA1 head structure: (a) (PDB: 1ti8); (b) "jelly roll" element topology; (c) the "jelly roll" diagram (Brändén \& Tooze, 1991).

characterized by a long structure with a globular head (Figure 2). The main structural element of the head is the "jelly roll", which is built of an 8-tape, antiparallel $\beta$ sheet (Figure 3). Between tapes 3 and 4 is a loop, with a short $\alpha$-helical region. The rest of the helix and the loop within the "jelly roll" structure (90-230 amino acid residues) form together with the receptor binding pocket (RBP). The amino acid residues which create the innermost part of RBP are largely maintained within the range of the serotype, while the ones that are located more externally express a certain degree of changeability (Mazur \& Marcey, 2011). The second HA2 subunit (221 amino acid residues, $20 \mathrm{kDa}$ ) consists of two $\alpha$-helices antiparallelly located (Figure 4). The longer is around $75 \AA$ in length and is built of 52 amino acid residues, whereas the shorter is $25 \AA$ in length and has 20 residues. Through this subunit, hemagglutinin is anchored in the virus's membrane (Lai \& Tamm, 2007; Mazur \& Marcey, 2011). As the HA1 unit is responsible for recognizing the receptor, the HA2 is responsible for fusing the virus membrane with the endosome membrane and for releasing the nucleocapsid. This 
fusion is possible thanks to the presence of the fusion peptide within the domain (Lai \& Tamm, 2007).

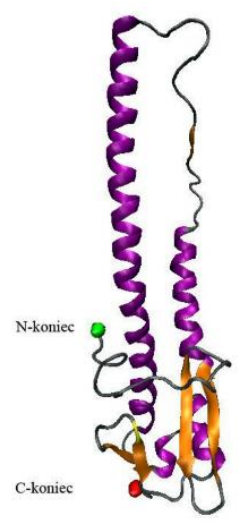

(a)

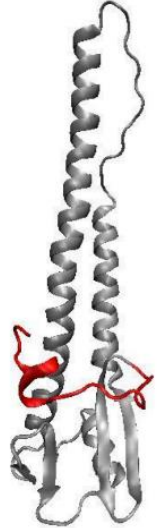

(b)
Figure 4. HA2 subunits: (a) he $\alpha$-helix structures have been marked in purple, while the $\beta$-sheets in orange and the $\mathrm{N}$-terminus in green and $\mathrm{C}$-terminus in red; (b) fusion peptide (red) (PDB: 1ti8).

\section{Trimer structure}

On the surface of the virus, hemagglutinin can be encountered in the form of a homotrimer (Figure 5) The trimeric HA complex is stabilized by the interaction of three main 3-helices of the core which form a triple roll. The stabilizing effect between the helices has two types of characters: hydrophobic interaction between the amino acid residues of the upper part of the roll and electrostatic force between the polar amino acids of the base of the roll (Mazur \& Marcey, 2011).

\section{Antigen determinants}

During a viral infection, HA plays an important role in the immune response. Together with NA, it is the first antigen that the system recognizes. The antibodies directed against HA have a neutralizing character and play a major part in fighting off the infection. The neutralization is a result of the antibodies binding with their antigen regions within the RBP. Thanks to the "escape mutants" method, a different number of antigen regions has been located on the hemagglutinin (antigen determinants), depending on the type (Ilyushina, Rudneva, Gambaryan, Tuzikov, \& Bovin, 2004; Kaverin et al., 2004). The number of epitopes fluctuates between 4 and 6 . For example, the $\mathrm{H} 3$ subtype has four antigen determinants: A - among others, encompasses the amino acid residues from 140 to 146; B - residues 187 196; C - encompasses the $276-280$ residue area and the disulfide bridge between Cys52 and Cys277; D -

residues 201-208 (Figure 6)(Wiley, Wilson, \& Skehel, 1981). The particular epitopes are located in the external, exposed areas of the loop structure, the "jelly roll" and the other locations on the HA "head". The spatial distribution of particular antigen determinants is largely constant, in various hemagglutinin serotypes. However, it is highly probable that even single changes within the epitopes allow the virus to escape immunological control and block the connection with the neutralizing antibodies (Wiley et al., 1981). For instance, one of the virus's protective mechanisms is to introduce a carbohydrate group or a glycosylation site within the epitope (llyushina et al., 2004; Nakamura et al., 2002).

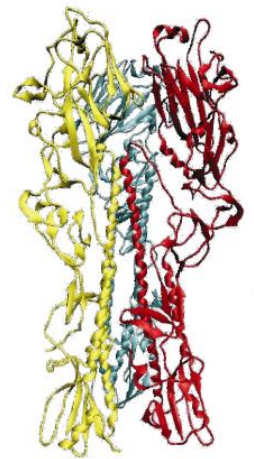

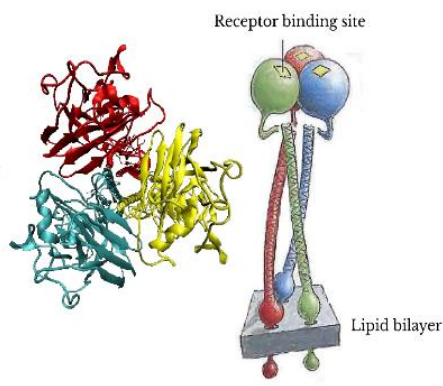

(b)
Figure 5. Haemagglutinin homotrimer structure (PDB: 1ruy); (a) View from the side; (b) View from above; (c) Diagram (Brändén \& Tooze, 1991).

\section{Hemagglutinin posttranslational modification}

Hemagglutinin undergoes a number of posttranslational modifications, out of which the most significant is glycosylation. The number of added oligosaccharide chains differs among the various isolates, but usually, it is between 3 and 7 per monomer. The glycosylation site, which is present in the HA core, is conserved in all the hemagglutinin subtypes of the influenza $A$ virus. In this region, there are three sites where the carbohydrates get added. Oligosaccharides have a significant homotrimer stabilization function. They also probably participate in the regulation of hemagglutinin transport within the cell. They are necessary for the normal storage and transport of hemagglutinin from the endoplasmic reticulum to Golgi apparatus and its further modification (Klenk, Wagner, Heuer, \& Wolff, 2002; R. Ohuchi, Ohuchi, Garten, \& Klenk, 1997). Oligosaccharides are known to play a significant biological part. Acquiring new glycosylation sites, especially in the area of the head and the site of the cut influences the interaction between the virus and the host's cell or the cell proteases. The sugars, which appear in the area or neighborhood of RBP, modify the 
hemagglutinins specificity and its affinity with the receptor. For the virus, a complete absence of glycans in the area is not beneficial, as it causes very strong bondage to the receptors and forces a stronger reaction of neuraminidase. However, a carbohydrate excess would cause very weak or impossible bondage and lack of infectious capacity (M. Ohuchi, Ohuchi, Feldmann, \& Klenk, 1997).

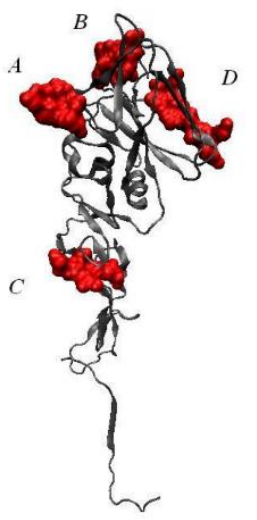

Figure 6. H3 haemagglutinin epitopes' location (PDB: 2hmg). The epitopes encompass the following residues: A - 140-146, B - 187-196, C - 276-280 and 52, D - 201208.

The key roles here are played by two asparagine residues (Asn) in positions 149 and 123, whose $\mathrm{N}$ glycosylation influences the receptor binding. In the case of $\mathrm{H} 1$ hemagglutinin, oligosaccharides added to both asparagine residues influence the $\mathrm{HA}$ ability to recognize $\alpha(2-3)$-glycosidic binding. The mutants which do not have these sugars possess the ability to recognize the $\alpha(2-6)$ binding. The glycosylation differences within RBP also determine the tissue specificity of the viruses (Wagner et al., 2001). Oligosaccharides which appear in the antigen determinant areas cause masking and blocking the access of neutralizing antibodies and, as a consequence, disturb the host's immune response. The influence of glycosylation within the loop, where the HAO precursor's cut takes place is the opposite. A larger amount of carbohydrates causes limited access to cell proteases, which in turn causes a decrease in the virus's pathogenicity.

\section{Hemagglutinin's role in the development cycle of the virus}

Hemagglutinin takes part in two key stages of the virus's replicative cycle. In the stage of the virus's penetration, it is responsible for the specific binding on the surface of the host's cell with a receptor. In the endosomes, on the other hand, it has the important role in the fusion of the virus's lipid membrane and the endosome's.

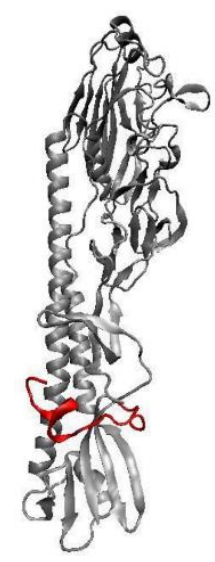

Figure 7. Fusion domain location (PDB: 1jsm).

\section{Receptor binding role}

Hemagglutinin is responsible for the species specificity of the virus, by different recognition and binding of sialic (neuraminic) acid, located in the host's cell within the glycoprotein oligosaccharides' chain, glycolipids and membrane glycoproteoglicans (Klenk et al., 2002). Sialic acid is connected to the sugar that precedes it (usually galactose) with two types of glycoside bindings, depending on the species. In the human receptors, the $\alpha(2-6)$-glycoside binding is dominant and is only recognized by three serotypes of hemagglutinin: $\mathrm{H} 1, \mathrm{H} 2$, H3. In birds, on the other hand, the a(2-3)-glycoside binding is dominant and recognized by all the $\mathrm{H} 1-\mathrm{H} 16$ serotypes. Organisms like swine possess both receptors on the surface of the cells, and thus a coinfection with both human and avian viruses might occur, as well as their rearrangement is possible (Russell, Stevens, Haire, Gamblin, \& Skehel, 2006). Besides, Kogure's teams' research proved that there are the $\alpha(2-3)$ type receptors on the epithelial cells of the human trachea (Kogure et al., 2006).

\section{Hemagglutinin role in the membrane fusion process}

After binding the sialic receptor, the virus penetrates the cell via endocytosis. Following the binding is a rapid change of $\mathrm{pH}$ in the endosomes, from neutral $(\mathrm{pH} \approx 7.4)$ to acidic $(\mathrm{pH} \approx 5.0)$. The lower $\mathrm{pH}$ activates conformational shifts of the HA2 hemagglutinin subunit, especially the fusion peptide, which leads to membrane fusion and release of a neuro capsid into the host's cell (Mazur \& Marcey, 2011). The fusion peptide (fusion domain) is located on the HA2 N-terminus (Figure 7), is built of around 20 amino acid residues 
(GLFGAIAGFIENGWEGMIDG) and has a hydrophobic characteristic (Brändén \& Tooze, 1991). In neutral pH, the fusion domain is hidden between the hydrophobic amino acid residues, while in an acidic environment it is uncovered and initiates the membrane fusion by connecting to the endosome membrane. Many fusion peptides from several hemagglutinin trimers create a single fusion site. Furthermore, a $\mathrm{pH}$ decrease induces a conformation change in HA2 and "bending" of the membrane towards it, which brings them closer together and facilitates the fusion.

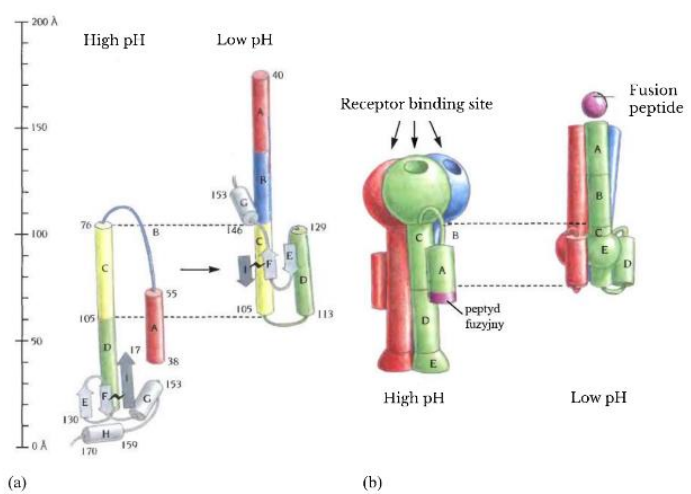

Figure 8. Haemagglutinin particle in different $\mathrm{pH}$ : (a) HA2 diagram; (b) trimer diagram (Brändén \& Tooze, 1991). The $\mathrm{pH}$ decrease causes a change in the HA2 conformation and helix reposition by around $100 \AA$, in the direction of the receptor binding site as well as a simultaneous approximation of the virus's membrane towards the endosome's membrane.

The HA2 structure diagram for different $\mathrm{pH}$ was presented in Figure 8. In a high $\mathrm{pH}$, helix $\mathrm{A}$, which ends with a fusion peptide, is close to the lipid membrane of the virus. The $\mathrm{pH}$ decrease induces changes within the $B$ area, and $A$ helix repositioning by around $100 \AA$ towards the site of receptor binding and thus brings the virus membrane towards the endosome membrane initializing their fusion (Brändén \& Tooze, 1991). In a low
$\mathrm{pH}$, the fusion peptide forms a boomerang-like structure, whose center is $\mathrm{Asn}^{12}$ (Figure 9). This structure indicates a certain symmetry and is built of two helices. It is stabilized by $\mathrm{Phe}^{9}$, $\mathrm{Il}^{10}$ (on the $\mathrm{N}$-terminus side) and by $\operatorname{Trp}^{14}$ (on the C-terminus side).

(a)

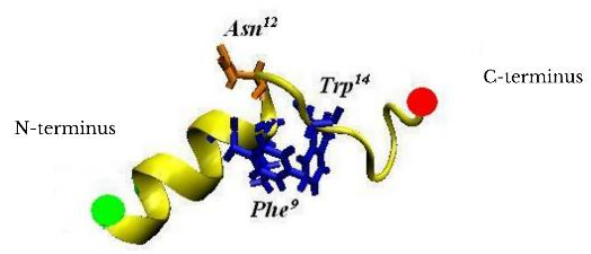

(b)

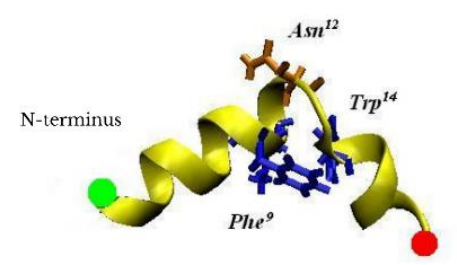

C-terminus

Figure 9. Fusion peptide structure: (a) $\mathrm{w} \mathrm{pH} \approx 7,0$ (PDB: 1ibn); (b) w pH $\approx 5,0$ (PDB: 1ibo).

The conformation change causes bending of the entire hemagglutinin particle and brings the membranes closer together. It is also suspected that the fusion domain influences the reposition and removal of water from the spaces between the merging membranes (probably due to the large content of hydrophobic amino acid residues) (Lai \& Tamm, 2007). An environment without water in the area is necessary for the fusion to occur. Besides, the changes caused by the $\mathrm{pH}$ decrease in the endosome are irreversible. In addition, hemagglutinin has two energy minimums (Figure 10), and the HA particle structure in a low $\mathrm{pH}(\approx 5,0)$ is more lasting than the particles in a higher $\mathrm{pH}(\approx 7,0)$ when it comes to energy. 
Table 1. Haemagglutinin cut sites' comparison [ClustalX2]. The red frame indicates the site of glycosylation $\left(\right.$ Asn $\left.^{319}\right)$; maintained sites $\left(\right.$ Pro $\left.^{321}\right)$; maintained cut sites_ $\left(\operatorname{Arg}^{330}-\mathrm{Phe}^{333}\right)$.

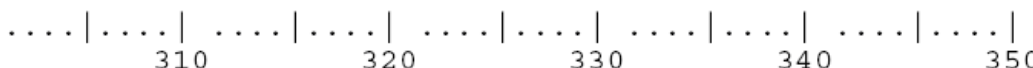

H1-human 01

H1-human 02

$\mathrm{H} 1$-human 03

H1-swine

H1-duck

H2 - human 01

H2 -human 02

H2 - human 03

H2-duck

H2 -pintail

H3-duck01

H3-duck 02

H3 - human

H4 - turnsto

H 4 - duck 01

H 4 -duck 02

H4 - chicken

H4-budgeri

H5-duck

H5-goose

H5-chicken

H5-human

H6-mallard

H6-mallard

H6 - turkey 0

H6 - turkey 0

H6-duck

H7-chicken

H7 - turkey

H7-mallard

H7-duck

H7 - rhea

H9- turkey

H9-duck

H9-chicken

H9-swine

H9-shovele

H10-mink

H10-chicke

H10-duck

H11-mallar

H11-chicke

H11-teal

H11-duck

H11 - ruddy

H13 -gullO1

H13 -gull 02

H13-duck

H13 -whale

H14-mall ar

H15-shearw

H15-duck

H16-gull

Clustal Co
ECPKYVRSAK LRMVTGLRNI PSIQS----R GLFGAIAGFI EGGWTGMVDG ECPKYVRSTK LRMVTGLRNI PSIQS----R GLFGAIAGFI EGGWTGMIDG ECPKYVRSAK LRMVTGLRNI PSIQS----R GLFGAIAGFI EGGWTGMVDG ECPKYVRSTK LRMVTGLRNI PSIQS----R GLFGAIAGFI EGGWTGMIDG ECPKYVKSTK LRMATGLRNV PSIQS---R RLFGAIAGFI EGGWSGMIYG ECPKYVKSEK LVLATGLRNV PQIES----R GLFGAIAGFI EGGWQGMVDG ECPKYVKSEK LVLATGLRNV PQIES----R GLFGAIAGFI EGGWQGMIDG ECPKYVKSEK LVLATGLRNV PQIES----R GLFGAIAGFI EGGWQGMVDG ECPKYVKSER LVLATGLRNV PQIES----R GLFGAIAGFI EGGWQGMVDG ECPKYVKSEK LVLATGLRNV PQMES----R GLFGAIAGFI EGGWQGMVDG ACPKYVKQNS LKLATGMRNV PEKQT----R GLFGAIAGFI ENGWEGMIDG ACPKYVKQNT LKLATGMRNV PEKQT----R GLFGAIAGFI ENGWEGMIDV ACPRYVKQNT LKLATGMRNV PEKQT----R GIFGAIAGFI ENGWEGMVDG DCPKYVKQGS LKLATGMRNI PEKAT---R GLFGAIAGFI ENGWQGLIDG DCPRYVKQGS LKLATGMRNI PEKAS----R GLFGAIAGFI ENGWQGLIDG DCPKYVKQGS LKLATGMRNI PEKAT----R GLFGAIAGFI ENGWQGLIDG DCPKYVKQGS LKLATGMRNI PEKAT----R GLFGAIAGFI ENGWQGLIDG ECPKYVKQGS LKLATGMRNV PEKAS----R GLFGAIAGFI ENGWQGLIDG ECPKYVKSNR LVLATGLRNT PQRERRRKKR GLFGAIAGFI EGGWQGMVDG ECPKYVKSNR LVLATGLRNT PQRERRRKKR GLFGAIAGFI EGGWQGMVDG ECPKYVKSNR LVLATGLRNS PQGERRRKKR GLFGAIAGFI EGGWQGMVDG ECPKYVKSSR LVLATGLRNS PQRESRRKKR GLFGAIAGFI EGGWQGMVDG ECPKYVKSKS LKLATGLRNV PQAET----R GLFGAIAGFI EGGWTGMVDG ECPKYVKSKN LKLATGLRNV PQVKT----R GLFGAIAGFI EGGWTGMVDG ECPKYVKSES LRLATGLRNN PRIET----R GLFGAIAGFI EGGWTGMIDG ECPKYVKSGS LRLATGLRNV PQIET---R GLFGAIAGFI EGGWTGMIDG ECPKYVKSES LRLATGLRNV PQIET----R GLFGAIAGFI EGGWTGMIDG KCPRYVKQES LLLATGMKNV PEIPKRR-RR GLFGAIAGFI ENGWEGLIDG KCPRYVKQES LLLATGMKNN PEIPKG---R GLFGAIAGFI ENGWEGLIDG KCPRYVKQES LMLATGMKNN PEIPKG---R GLFGAIAGFI ENGWEGLIDG KCPRYVKQES LLLATGMKNN PEIPKG---R GLFGAIAGFI ENGWEGLIDG KCPRYVKQPS LLLATGMRNV PENPKT---R GLFGAIAGFI ENGWEGLIDG NCPKYVGVKS LKLAVGLRNV PAASA--- R GLFGAIAGFI EGGWPGLVAG NCPKYVGVKS LKLAVGLRNV PAASD----R GLFGAIAGFI EGGWPGLVAG NCPKYVGVKS LKLAVGLRNV PARSS----R GLFGAIAGFI EGGWSGLVAG NCPKYVGVKS LKLAVGLRNV PARSS----R GLFGAIAGFI EGGWSGLVAG NCPKYVRVKS LKLAVGLRNN PARSS----R GLFGAIAGFI EGGWPGLVAG QCPKYVNQRS LLLATGMRNV PEVVQG---R GLFGAIAGFI ENGWEGMVDG QCPKYVNKKS LMLATGMRNV PEIMQG---R GLFGAIAGFI ENGWEGMVDG QCPKYVNKRS LMLATGMRNV PEIIQG---R GLFGAIAGFI ENGWEGMVEA DCPKYVNVKS LKLATGLRNV PAIAT----R GLFGAIAGFI EGGWPGLING DCPKYVNVKS LKLATGLRNV PAIAT----R GLFGAIAGFI EGGWPGLING DCPKYVNVKS LKLATGLRNV PAIAT---R GLFGAIAGFI EGGWPGLING DCPKYVNVKS LKLATGLRNV PAIAA----R GLFGAIAGFI EGGWPGLING DCPKYVNVKS LKLATGLRNI PAIAT----R GLFGAIAGFI EGGWPGLING DCPKYIKSGQ LKLATGLRNN PAISN----R GLFGAIAGFI EGGWPGLING DCPKYIKSGQ LKLATGLRNV PAISN----R GLFGAIAGFI EGGWPGLING DCPKYIKSGQ LKLATGLRNN PAISN----R GLLGAIAGFI EGGWPGLING NCPKYIKSGQ LKLATGLRNV PAISN----R GLFGAIAGFI EGGWPGLING NCPKYVKQGS LMLATGMRNI PGKQA----K GLFGAIAGFI ENGWQGLIDG KCPRYVKQSS LPLALGMKNV PEKIRT---R GLFGAIAGFI ENGWEGLIDG RCPRYVKQSS LPLALGMKNN PEKIHT---R GLFGAIAGFI ENGWEGLIDG DCPKYIKSGQ LKLATGLRNV PSVGE----R GLFGAIAGFI EGGWPGLING

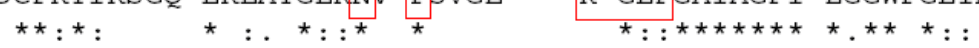


However, reaching the second minimum is impossible in a neutral $\mathrm{pH}$. It is only possible to overcome the energy barrier and reach the global energetic minimum of the particle if the environment is acidified. After the minimum is reached, no temperature or $\mathrm{pH}$ changes cause the

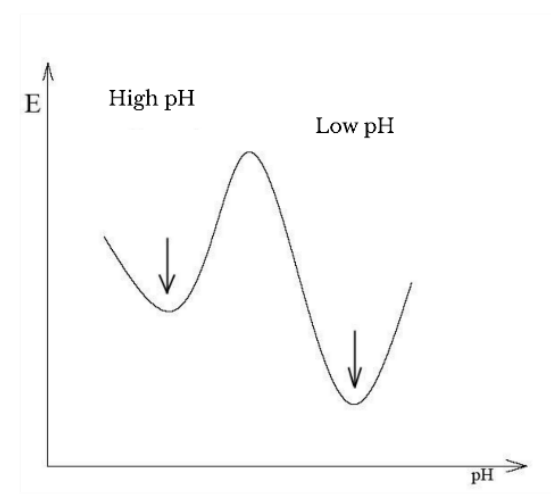

Figure 10. A diagram of haemagglutinin conformation energy against $\mathrm{pH}$.

return of the HA conformation to its initial form (Brändén \& Tooze, 1991).

\section{Comparison of hemagglutinins}

\section{The site of the cut}

To work properly, hemagglutinin must be activated. The most important stage of activation is the HAO precursor's proteolytic cut by the cell proteases into HA1 (amino terminal) and HA2 (carboxy-terminal) (Klenk et al., 2002). The process takes places either after hemagglutinin is bound to the cell membrane (in the case of an influenza virus with low pathogenicity, like LPAI) or as the new viral particles are composed (in the case of highly pathogenic strains of the influenza virus, like HPAl). The proteolytic hemagglutinin cut occurs within the loop (Figure 13) around the amino acid residue at position 330 , at the $\mathrm{N}$-terminus of the chain. The sites of the cut have two types of built. The single arginine residue, which is common in all serotypes $(\mathrm{H} 1$ $\mathrm{H} 16)$ is recognized by extracellular trypsin-like proteases, i.e. trypsin, blood coagulation factor $\mathrm{X}$, tryptase Clare, plasmin, miniplasmin or TMPRSS2, which usually are tissue-specific. In the highly pathogenic strains (HPAI), $\mathrm{H} 5$ and $\mathrm{H} 7$ there are additional $-\mathrm{R}-\mathrm{X}-\mathrm{R} / \mathrm{K}-\mathrm{R}-$ elements, also recognized by the common sublysine-like proteases: furin and PC6 (Protein Convertase 6).

These proteases are located in the cells, mainly in the TNG (trans-Golgi network), which causes hemagglutinin to activate, when still inside the host's cell during the protein-maturing stage. The effect of such mechanism is the production of activated viruses, which are capable of infecting every kind of cells (Garten et al., 2004; Zhirnov, Vorobjeva, Ovcharenko, \& Klenk, 2003). The larger the number of the arginine residues within the site of the cut, the larger the virus's capacity to infect.

The proteolysis process is also affected by the proximity of the site of the cut, especially the glycosylation sites (e.g. asparagine residues - Asn, N). As it was mentioned, the glycan chains can limit proteases' assess and decrease the activation efficiency. The HA cut is a factor which conditions the influenza virus's infectiveness and all the changes within this area influence the pathogenicity of a particular strain (Zhirnov et al., 2003).

In table 1 and 2 there is a comparison of the sites of the cuts of 53 amino acid sequences of 14 various hemagglutinin types. As it can be noticed, the $\mathrm{H} 5$ and $\mathrm{H} 7$ are highly pathogenic virus types. In some cases of H9 (A/Shoveler//ran/G54/03(H9), A/swine/Hong Kong/9/98-MA(H9N2), $\quad$ A/chicken/Shandong /1/02(H9N2)) and H15 (A/Shearwater/West Australia/2576/79(H15N9)), extra arginine occurs. This may increase the probability of a proteolytic cut and pose a world-scale threat in the future. Additionally, asparagine can be observed in the $\mathrm{H} 13$ serotype. The glycosylation site certainly makes the access to the site of the cut much more difficult for proteases. It results in low pathogenicity and lowered incidence connected with this virus.

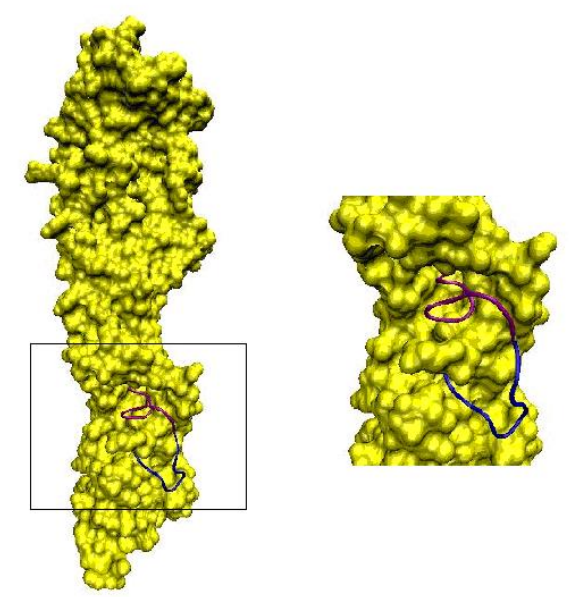

Figure 11. Crystal structure of a haemagglutinins precursor. The HAO precursor's cut area into subunits has been marked: HA1 (purple) and HA2 (blue) (PDB: 1ha0). 


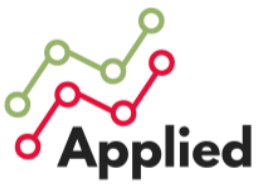 \\ Biosciences}

Table 2. Haemagglutinin cut sites' comparison [ClustalX2] - the arrow indicates the HA0 cut site.

HA

\section{H1-human01 \\ H1-human02 \\ H1-human03 \\ H1-swine \\ H1-duck \\ H2-human01 \\ H2-human02 \\ H2-human03 \\ H2-duck \\ H2-pintail}

H3-duck01

H3-duck02

H3-human

H4-turnsto

H4-duck01

H4-duck02

H4-chicken

H4-budgeri

H5-duck

H5-goose

H5-chicken

H5-human

H6-mallard
H6-mallard
H6-turkey0
H6-turkey0
H6-duck
H7-chicken
H7-turkey
H7-mallard
H7-duck
H7-rhea

H9-turkey

H9-duck

H9-chicken

$$
\text { Strain }
$$

A/Malaysia/760/2005(H1) A/Yamagata/120/1986(H1N1)

A/Bangkok/1940/2004(H1)

A/swine/Cambridge/39(H1N1)

A/duck/HK/36/1976(H1)

A/Korea/426/68(H2N2)

A/Singapore/1/57 (H2N2)

A/Izumi/5/65(H2N2)

A/Peking duck/Potsdam/1689-4/85 (H2N3) A/Pintail/Praimoric/625/76 (H2N2)

A/DK/HK/7/1975(H3)

A/duck/Hong Kong/231/77(H3)

A/human/Ohio/2006(H3N2)

A/ruddy turnstone/NJ/47/1985(H4N6)

A/duck/Czeckoslovakia/1956(H4N6) A/duck/Alberta/28/1976(H4N6)

A/chicken/Alabama/1/1975(H4N8)

A/ budgerigar/Hokkaido/1/77 (H4N6)

A/Duck/Hong Kong/380.5/2001(H5N1)

A/Goose/Hong Kong/3014.5/2000(H5N1)

A/chicken/Niger/2130-7/2006(H5N1)

A/Indonesia/TLL012/2006(H5N1)

A/Mallard Duck/Alberta/211/85 (H6N2)

A/mallard/Ohio/653/2002(H6N2)

A/turkey/Germany/R30/99(H6N1)

A/turkey/France/04239/2004(H6N2)

A/duck/France/03136/2003(H6N2)

A/chicken/Germany/R28/03(H7N7)

A/turkey/Italy/472/99(H7N1)

A/mallard/Italy/299/05(H7N7)

A/duck/Jiangxi/1760/03(H7N7)

A/rhea/North Carolina/39482/1993(H7N1)

A/turkey/Germany/R33/96(H9N2)

A/duck/Jiangxi/1588/00(H7N7)

A/chicken/Shandong/1/02(H9N2)
Cut site

$\begin{array}{llllllllllllll}\mathrm{P} & \mathrm{S} & \mathrm{I} & \mathrm{Q} & \mathrm{S} & - & - & - & - & \mathbf{R} & \downarrow & \mathbf{G} & \mathbf{L} & \mathrm{F} \\ \mathrm{P} & \mathrm{S} & \mathrm{I} & \mathrm{Q} & \mathrm{S} & - & - & - & - & \mathbf{R} & \downarrow & \mathbf{G} & \mathbf{L} & \mathrm{F} \\ \mathrm{P} & \mathrm{S} & \mathrm{I} & \mathrm{Q} & \mathrm{S} & - & - & - & - & \mathbf{R} & \downarrow & \mathbf{G} & \mathbf{L} & \mathrm{F} \\ \mathrm{P} & \mathrm{S} & \mathrm{I} & \mathrm{Q} & \mathrm{S} & - & - & - & - & \mathbf{R} & \downarrow & \mathbf{G} & \mathbf{L} & \mathrm{F} \\ \mathrm{P} & \mathrm{S} & \mathrm{I} & \mathrm{Q} & \mathrm{S} & - & - & - & - & \mathbf{R} & \downarrow & \mathbf{G} & \mathbf{L} & \mathrm{F}\end{array}$

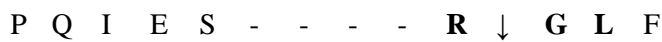

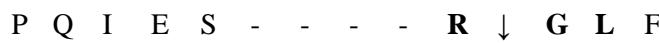

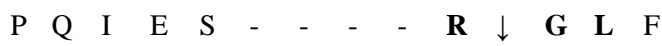

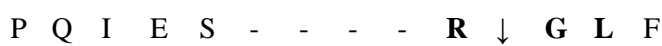

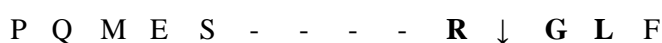

$\begin{array}{lllllllllllllll}\mathrm{P} & \mathrm{E} & \mathrm{K} & \mathrm{Q} & \mathrm{T} & - & - & - & - & \mathbf{R} & \downarrow & \mathbf{G} & \mathbf{L} & \mathrm{F}\end{array}$

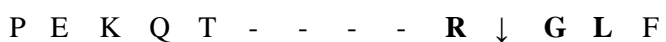

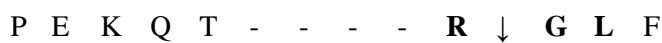

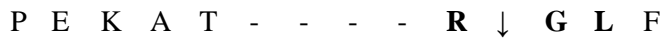

$\begin{array}{llllllllllllll}\mathrm{P} & \mathrm{E} & \mathrm{K} & \mathrm{A} & \mathrm{S} & - & - & - & - & \mathbf{R} & \downarrow & \mathbf{G} & \mathbf{L} & \mathrm{F}\end{array}$

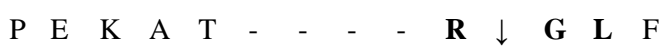

$\begin{array}{lllllllllllllll}\mathrm{P} & \mathrm{E} & \mathrm{K} & \mathrm{A} & \mathrm{T} & - & - & - & - & \mathbf{R} & \downarrow & \mathbf{G} & \mathbf{L} & \mathrm{F}\end{array}$

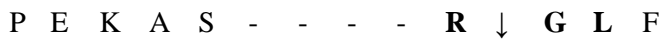

$\begin{array}{llllllllllllll}\mathrm{P} & \mathrm{Q} & \mathbf{R} & \mathrm{E} & \mathbf{R} & \mathbf{R} & \mathbf{R} & \mathrm{K} & \mathrm{K} & \mathbf{R} & \downarrow & \mathbf{G} & \mathbf{L} & \mathrm{F}\end{array}$

$\begin{array}{llllllllllllll}\mathrm{P} & \mathrm{Q} & \mathbf{R} & \mathrm{E} & \mathbf{R} & \mathbf{R} & \mathbf{R} & \mathrm{K} & \mathrm{K} & \mathbf{R} & \downarrow & \mathbf{G} & \mathbf{L} & \mathrm{F}\end{array}$

$\begin{array}{llllllllllllll}\mathrm{P} & \mathrm{Q} & \mathrm{G} & \mathrm{E} & \mathbf{R} & \mathbf{R} & \mathbf{R} & \mathrm{K} & \mathrm{K} & \mathbf{R} & \downarrow & \mathbf{G} & \mathbf{L} & \mathrm{F}\end{array}$

$\begin{array}{llllllllllllll}\mathrm{P} & \mathrm{Q} & \mathbf{R} & \mathrm{E} & \mathrm{S} & \mathbf{R} & \mathbf{R} & \mathrm{K} & \mathrm{K} & \mathbf{R} & \downarrow & \mathbf{G} & \mathbf{L} & \mathrm{F}\end{array}$

$\begin{array}{llllllllllllll}\mathrm{P} & \mathrm{Q} & \mathrm{A} & \mathrm{E} & \mathrm{T} & - & - & - & - & \mathbf{R} & \downarrow & \mathbf{G} & \mathbf{L} & \mathrm{F} \\ \mathrm{P} & \mathrm{Q} & \mathrm{V} & \mathrm{K} & \mathrm{T} & - & - & - & - & \mathbf{R} & \downarrow & \mathbf{G} & \mathbf{L} & \mathrm{F} \\ \mathrm{P} & \mathrm{Q} & \mathrm{I} & \mathrm{E} & \mathrm{T} & - & - & - & - & \mathbf{R} & \downarrow & \mathbf{G} & \mathbf{L} & \mathrm{F} \\ \mathrm{P} & \mathrm{Q} & \mathrm{I} & \mathrm{E} & \mathrm{T} & - & - & - & - & \mathbf{R} & \downarrow & \mathbf{G} & \mathbf{L} & \mathrm{F} \\ \mathrm{P} & \mathrm{Q} & \mathrm{I} & \mathrm{E} & \mathrm{T} & - & - & - & - & \mathbf{R} & \downarrow & \mathbf{G} & \mathbf{L} & \mathrm{F}\end{array}$

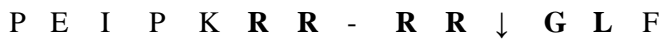

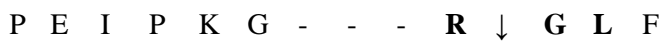

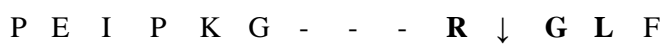

$\begin{array}{llllllllllllll}\mathrm{P} & \mathrm{E} & \mathrm{I} & \mathrm{P} & \mathrm{K} & \mathrm{G} & - & - & - & \mathbf{R} & \downarrow & \mathbf{G} & \mathbf{L} & \mathrm{F}\end{array}$

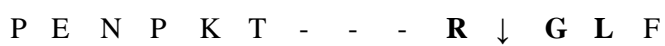

$\begin{array}{llllllllllllll}\mathrm{P} & \mathrm{A} & \mathrm{A} & \mathrm{S} & \mathrm{A} & - & - & - & - & \mathbf{R} & \downarrow & \mathbf{G} & \mathbf{L} & \mathrm{F}\end{array}$

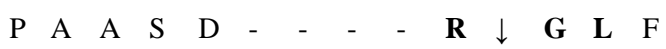

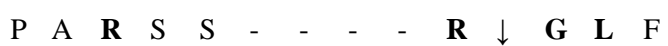




\begin{tabular}{|c|c|c|c|c|c|c|c|c|c|c|c|c|c|c|c|}
\hline H9-swine & A/swine/Hong Kong/9/98-MA(H9N2) & $\mathrm{P}$ & A & $\mathbf{R}$ & $\mathrm{S}$ & $\mathrm{S}$ & - & - & - & - & $\mathbf{R}$ & $\downarrow$ & G & $\mathbf{L}$ & $\mathrm{F}$ \\
\hline H9-shovele & A/shoveler/Iran/G54/03(H9) & $\mathrm{P}$ & A & $\mathbf{R}$ & $\mathrm{S}$ & $\mathrm{S}$ & - & - & - & - & $\mathbf{R}$ & $\downarrow$ & $\mathbf{G}$ & $\mathbf{L}$ & $\mathrm{F}$ \\
\hline H10-mink & A/mink/Sweden/1984(H10N4) & $\mathrm{P}$ & $\mathrm{E}$ & $\mathrm{V}$ & $\mathrm{V}$ & Q & G & - & - & - & $\mathbf{R}$ & $\downarrow$ & G & $\mathbf{L}$ & $\mathrm{F}$ \\
\hline H10-chicke & A/chick/ Germany/N/49 (H10N7) & $\mathrm{P}$ & $\mathrm{E}$ & I & M & Q & $\mathrm{G}$ & - & - & - & $\mathbf{R}$ & $\downarrow$ & $\mathbf{G}$ & $\mathbf{L}$ & $\mathrm{F}$ \\
\hline H10-duck & A/Duck/Indonesia/Jakarta Utara1631-29/06(H10) & $\mathrm{P}$ & $\mathrm{E}$ & I & I & Q & $\mathrm{G}$ & - & - & - & $\mathbf{R}$ & $\downarrow$ & $\mathbf{G}$ & $\mathbf{L}$ & $\mathrm{F}$ \\
\hline H11-mallar & A/mallard/MN/346246/2000(H11N9) & $\mathrm{P}$ & A & I & A & $\mathrm{T}$ & - & - & - & - & $\mathbf{R}$ & $\downarrow$ & $\mathbf{G}$ & $\mathbf{L}$ & $\mathrm{F}$ \\
\hline H11-chicke & A/chicken/NJ/4236-18/1998(H11N3) & $\mathrm{P}$ & $\mathrm{A}$ & I & A & $\mathrm{T}$ & - & - & - & - & $\mathbf{R}$ & $\downarrow$ & $\mathbf{G}$ & $\mathbf{L}$ & $\mathrm{F}$ \\
\hline H11-teal & A/green-winged teal/LA/9GW/1987(H11N9) & $\mathrm{P}$ & A & I & A & $\mathrm{T}$ & - & - & - & - & $\mathbf{R}$ & $\downarrow$ & $\mathbf{G}$ & $\mathbf{L}$ & $\mathrm{F}$ \\
\hline H11-duck & A/duck/546/1974(H11N9) & $\mathrm{P}$ & A & I & A & A & - & - & - & - & $\mathbf{R}$ & $\downarrow$ & $\mathbf{G}$ & $\mathbf{L}$ & $\mathrm{F}$ \\
\hline H11-ruddy & A/ruddy turnstone/NJ/650678/2002(H11N4) & $\mathrm{P}$ & A & I & A & $\mathrm{T}$ & - & - & - & - & $\mathbf{R}$ & $\downarrow$ & $\mathbf{G}$ & $\mathbf{L}$ & $\mathrm{F}$ \\
\hline H13-gull01 & A/gull/Maryland/704/1977(H13N6) & $\mathrm{P}$ & A & I & $\mathrm{S}$ & $\mathbf{N}$ & - & - & - & - & $\mathbf{R}$ & $\downarrow$ & G & $\mathbf{L}$ & $\mathrm{F}$ \\
\hline H13-gull02 & A/gull/Astrakhan/227/1984(H13N6) & $\mathrm{P}$ & A & I & $\mathrm{S}$ & $\mathbf{N}$ & - & - & - & - & $\mathbf{R}$ & $\downarrow$ & G & $\mathbf{L}$ & $\mathrm{F}$ \\
\hline H13-duck & A/duck/Siberia/272PF/1998(H13N6) & $\mathrm{P}$ & A & I & $\mathrm{S}$ & $\mathbf{N}$ & - & - & - & - & $\mathbf{R}$ & $\downarrow$ & $\mathbf{G}$ & $\mathbf{L}$ & $\mathrm{F}$ \\
\hline H13-whale & A/whale/Maine/328/1984(H13N2) & $\mathrm{P}$ & A & I & $\mathrm{S}$ & $\mathbf{N}$ & - & - & - & - & $\mathbf{R}$ & $\downarrow$ & $\mathbf{G}$ & $\mathbf{L}$ & $\mathrm{F}$ \\
\hline H14-mallar & A/mallard/Astrakhan(Gurjev)/263/1982(H14N5) & $\mathrm{P}$ & $\mathrm{G}$ & $\mathrm{K}$ & Q & A & - & - & - & - & $\mathbf{R}$ & $\downarrow$ & $\mathbf{G}$ & $\mathbf{L}$ & $\mathrm{F}$ \\
\hline H15-shearw & A/shearwater/West Australia/2576/79(H15N9) & $\mathrm{P}$ & $\mathrm{E}$ & $\mathrm{K}$ & I & $\mathbf{R}$ & $\mathrm{T}$ & - & - & - & $\mathbf{R}$ & $\downarrow$ & $\mathbf{G}$ & $\mathbf{L}$ & $\mathrm{F}$ \\
\hline H15-duck & A/duck/Australia/341/83(H15N8) & $\mathrm{P}$ & $\mathrm{E}$ & $\mathrm{K}$ & I & $\mathrm{H}$ & $\mathrm{T}$ & - & - & - & $\mathbf{R}$ & $\downarrow$ & $\mathbf{G}$ & $\mathbf{L}$ & $\mathrm{F}$ \\
\hline H16-gull & A/black-headed gull/Sweden/5/99(H16N3) & $\mathrm{P}$ & $\mathrm{S}$ & $\mathrm{V}$ & $\mathrm{G}$ & $\mathrm{E}$ & - & - & - & - & $\mathbf{R}$ & $\downarrow$ & $\mathbf{G}$ & $\mathbf{L}$ & $\mathrm{F}$ \\
\hline
\end{tabular}

Hemagglutinin's precursor has been presented in Figure 11. The subunit HA1 fragment has been marked in purple, while the HA2 fragment in blue. Figure 12 presents five hemagglutinin structures with marked fragments of subunits, after the HAO precursor's cut. The general structure of the site of the cut may be similar. There is a noticeable cleavage with the sector that is recognized by the cell proteases. Four of the shown structures are very similar. Only the HA2 hemagglutinin $\mathrm{H} 7$ subunit does not create a helical fragment on the $\mathrm{N}$ terminus.

\section{Receptor binding's site}

The site of the sialic acid's receptor binding is located in the globular part of hemagglutinin. It adopts the form of a longitudinal, recessed pocket and is between the 90th and 230th amino acid residue. On the homotrimer, there are three anti-receptor sites (one on each monomer). The three fragments of the head play the most important part in the process of the head binding: helix 190 around the 190 amino acid residue (190-198 residue), loop 130 (135-138) and loop 220 (221-228) (Figure 13) (Russell et al., 2006). Within the site of the binding, maintained amino acid residues can be identified: $\operatorname{Tyr}^{98}$, $\operatorname{Trp}^{153}$, His ${ }^{183}$, Tyr ${ }^{195}$, which through hydrogen reaction stabilize the connections between the sialic acid of the receptor with the binding site on the hemagglutinin surface (Figure 14, Table 3, 4) (Martín et al., 1998). 
Table 3. Comparison of fragments of the haemagglutinin receptor (RBP) binding site [ClustalX2]. The red frames indicate maintained sites, which serve a significant role in stabilizing the sialic acid and haemagglutinin binding.

H1-human01
H1-human03
H1-human02
H1-gwine
H1-duck
H2-human01
H2-human03
H2-human02
H2-duck
H2-pintail
H3-duck01
H3-duck02
H3-human
H4-turnsto
H4-duck01
H4-duck02
H4-chicken
H4-budgeri
H5-duck
H5-goose
H5-chicken
H5-human
H6-mallard
H6-mallard
H6-turkey0
H6-turkey0
H6-duck
H7-chicken
H7-turkey
H7-mallard
H7-duck
H7-rhea
H9-turkey
H9-duck
H9-chicken
H9-gwine
H9-shovele
H10-mink
H10-chicke
H10-duck
H11-mallar
H11-chicke
H11-teal
H11-duck
H11-ruddy
H13-gull01
H13-gul102
H13-duck
H13-whale
H14-mallar
H15-shearw
H15-duck
H16-gul1

H1-human01

H1-swine

H1-duck

H2 - human 03

H2 - human 02

H2 -duck

H2 -pintail

H3 - duck 02

H3 -human

H4 - turnato

H4-duck 01

H4-duck 02

H4 -budgeri

H5-duck

H5-chicken

H5-human

H6-mallard

H6-mallard

H6-duck

H7-chicken

-turkey

H7-duck

H9-duck

H9-chicken

H9-swine

H9-shovel

H10-mink

H10-duck

H11-mallar

H11-chick

H11-tea

H11-ruddy

H13 -gullo1

H13-gullo2

H13 -whale

H14-mallar

H15-duck

H16-gull

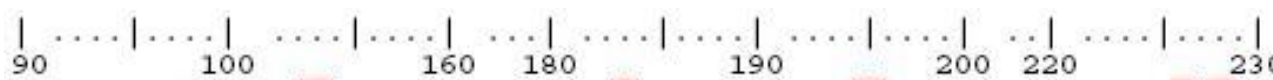
P NPENGTণYPG LLWTTGKNGL LVLW GVHHPPNIGD QRALYHTENA IKR PKVRDQAGRI P NPENGTCYEG LLWETGKNGL LVLW GVHHPPNIGD QRALYHTENA IKR PKVRDQAGRI P NSENGTCYPG LLWLTEKNGL LVLW GVHHPSNIGD QRAIYHTENA IKR PKVRGQEGRI P NSETGACYPG LLWLTKKGNS LVLW GVHHPSNSNN QQTLYHNANA AR PKVRDQHGRM S NSENGTCYPG LLWITKKGTS LVIW GVHHPPTATB QQSIYYNADA IAR PKVRGQAGRL B NPRYSLCYPG MVWLTRKGSN LIIW GYHHPNDBAB QRALYQNVGT AAR PKVNGLARRM B NPRYSLCYFG MYWTTKKGPN LIIW GYHHPNDEAB QRALYQBVGT AR PKVNGLSSRM B NPRDGLCYPG MVWTEKGSN LIIW GVHHPNDBKE QRTLYQNVGT ITR PKVNGLSSRM B NPRNGLCYFG MYWTTKKGSN LIIW GVHHPNDBTB QRTLYQNVGT ITR PKVNGQAGRM B NPRNGLCYPG MYWTTKKGSN LIIW GYHHPNDBAE QRTLYQNVGT ITR PNVNGQAGRM R GNAFSSCYPY LNWLTKSGST LYIW GUHHPSTNQB QTNLYVQASG ISR PWVRGQGGRI R SNAYSNCYPY LNWLTKSGST LYIW GIHHPSTSQB QTTLYVQASG ISR PWVRGQAGRI R SKAYSNCYPY LNWETHLKFK LYIW GYHHPGTDND QIFLYAQASG ISR PRVRNIASRI R PTAVDTCYPF LNWLTKSGNA LYIW GVHHPSTDTE QTNLYKNNPG ISG PLVRGQAGRI R PNAVDTCYPF LNWLVKSGNA LYIW GVHHPSTDTB QTNLYKINNPG ISR PLVRGQGGRV R PTAVDTCYPF LNW_TKSGDA LYIW GWHHPSTDTE QTNLYKINNG ISR PWVRGQAGRI R PTAVDTCYPF LNWETKSGNA LYIW GYHHPSTDTE QTNLYBNNPG ISR PWVRGQGGRI R PNAVDTCYPF LNWLVKSGNA LYIW GVHHPSTDTB QTNLYKINNG ISR PLVRGQGGRI A NPANDLCYPG VVWLIKKNSA LVLW GIHHPNDAAE QTKLYQNPTT ITR SKVNGQRGRM A SPANDLCYPG VVWLIKKNSA LVLW GIHHPNDAAE QIKLYONPTT ITR SKVNGQRGRM I NPANDLCYPG VVW-IKKDNA LVLW GIHHPNDAAB QTRLYONPTT ITR SKVNGQAGRM A NPTNDLCYPG VVWLIKKNST LVLW GIHHPNNBEE QTRLYONPTT ITR SKVNGQEGRM P DAQNGICYPG LLWIIKRSDP LYFW GYHXPPBEVB QANLYGIGTR IGR PPANGQFGRI P DAKNGICYEG LLWIIKKSDP LYFW GYHHPPDDVB QANLYGLGTR DR PPANGEFGRI P TAQNGICYPG LIWIIKKSAA LYFW GYHHPPDTNB QNTLYGSGDR P TAQNGICYPG LLWIIKKSAA LYFW GVHHPPDTNB QNTLYGSGDR P TAQNGICYPG LIWIIKKSAA LYFW GYHHPPDTNB ONTLYGSGDR R BGSD-VCYPG MIWLLSNTDN LIIW GIHHSGSTTB QTKLYGSGNK R BGSD-VCYFG MKWLLSNTDN LIIW GIHHSGSTTB QTKLYGSGNK R BGSD-VCYPG MIWLLSNTDN LITW GIHHSGSTTE QTKLYGSGNK R BGSD-VCYPG MKWLLSNTDN LIIW GIHHSGSTTB QTKLYGSGNK R BGND-VCYPG MKWLLSNSDN LIVW GIHHPGSTTB QTKLYGSGNK S SAVNGMCYPG MRWTTHKSNS LFMW GIHHPPTDTE QTNLYKKADT

$S$ SAINGMCYFG MRWETHKSNS LFMW GIHHPPTDTE QTNLYKKADT

P SAVNGMCYEG MRWETQKDNA LFMW GIH P TDTA QTNLYTRADT

P SAVNGMCYFG MRWLTQKNNA LFMW GIHHPFTDTV QTNLYTRTDT S SAVNGTCYPG MRWLTQKSGS LFVW GIHHPPTBAA QTNLYTRTDT B NAIA-HCYPG LIWEVSKGQN LIIW GIHAPSSTQB KNDLYGTQSL K NAIA-YCYPG VIWLVSKGQN LIIW GIHHPSSTQB KNDLYGTQSL D NAIA-YCYPG LKWLVSKGQN LIMW GIHHPSSTQB KNDLYGTQSL P NPINGIYYPG MYWLIHQSGT LMVW GVHHPATLKE HQDLYKKDSS P NPVNGICYPG MVWLIHQSGT LMVW GVHHPATLKE HQDLYKKDSS P NPVNGICYFG MVWLIHQSGT LMVW GYHHPATLKB HQDIYKKDNS P NPINGICYPG MYWLIHQSET LMVW GVHHPATLKE HQDLYKKDNS P NPANGICYPG MVWLIHQSGT LMVW GVHHPSSLQB HRDLYKKDIS 'P AAPHGLCYEG LYWFIKKNNR LVLW GIHHPVSVDE TKTLYNNSDP IP SAPHGLCYFG LVWFVBRGKQ LVMW GIHHPVSTDE ARKLYMNNDP IP GAPHGLCYPG LVWFVKKNNR LVLW GIHHPVSVBE TKTLYNNSDP IP SAPHGLYYPG LVWFVKKGNS LVMW GLHHPVSTDB TKSLYNNSDP R PTAVDTCYPF LNW_TKANGN LYLW GVHHPSSDNB QTDLYKVATG R NSSD-ICYPG MKWESSSNQV LIVW GYHASSSLDE QNKLYGTGNK R NSSD-ICYPG MKWLLSSNQV LIVW GYHHSSSLDE QNKLYGAGNK IP NAPNKLCFFG LVWIVKKNGK LVLW GIHHPDTETT AINLYASKNP
AR PAVNGQEGRI AR PAVNGQFGRI AR PAVNGQAGRI IAR PQVNGQAGRI IAR PQVNGQGGRI iAR PQVNGQEGRI IAR PQVNGQFGRI IAR PQVNGQEGRI IPR PLVNGQGGRI IPR PLVNGOQGRI IPR PLVNGQDGRI IPR PLVNGLHGRI IPR PLVNGLGGRI IAR PQVNGQ GGRI AR PQVNGQEGRI AR PQVNGQAGRI TR HKVNGQ AGRM TR PKVNGQ\#GRM TR PKVNGQAGRM TR PKVNGQ AGRM AR PAVNGQAGRM VR PGYNGQA SWM IR PGYNGQ सSWM VR PGYNGQF SWM VR PGYNGQ ASHM SR PRVRNQAGRI AR PKVNGQAGRI DR PKVNGQAGRI TR IG-DGQFISM 
Table 4. Comparison of the fragments of the haemagglutinin receptor (RBP) binding site - the highlight of the significant maintained amino acid residues.

\section{H1-human01 \\ H1-human03 \\ H1-human02 \\ H1-swine \\ H1-duck \\ H2-human01 \\ H2-human03 \\ H2-human02 \\ H2-duck \\ H2-pintail}

H3-duck01

H3-duck02

H3-human

H4-turnsto

H4-duck01

H4-duck02

H4-chicken

H4-budgeri

H5-duck

H5-goose

H5-chicken

H5-human

H6-mallard

H6-mallard

H6-turkey0

H6-turkey0

H6-duck

H7-chicken

H7-turkey

H7-mallard

H7-duck

H7-rhea

H9-turkey

H9-duck

\section{A/Malaysia/760/2005(H1)}

A/Bangkok/1940/2004(H1)

A/Yamagata/120/1986(H1N1)

A/swine/Cambridge/39(H1N1)

A/duck/HK/36/1976(H1)

A/Korea/426/68(H2N2)

A/Izumi/5/65(H2N2)

A/Singapore/1/57 (H2N2)

A/Peking duck/Potsdam/1689-4/85 (H2N3)

A/Pintail/Praimoric/625/76 (H2N2)

A/DK/HK/7/1975(H3)

A/duck/Hong Kong/231/77(H3)

A/human/Ohio/2006(H3N2)

\begin{abstract}
A/ruddy turnstone/NJ/47/1985(H4N6)
A/duck/Czeckoslovakia/1956(H4N6)

A/duck/Alberta/28/1976(H4N6)

A/chicken/Alabama/1/1975(H4N8)

A/ budgerigar/Hokkaido/1/77 (H4N6)
\end{abstract}

A/Duck/Hong Kong/380.5/2001(H5N1)

A/Goose/Hong Kong/3014.5/2000(H5N1)

A/chicken/Niger/2130-7/2006(H5N1)

A/Indonesia/TLL012/2006(H5N1)

A/Mallard Duck/Alberta/211/85 (H6N2)

A/mallard/Ohio/653/2002(H6N2)

A/turkey/Germany/R30/99(H6N1)

A/turkey/France/04239/2004(H6N2)

A/duck/France/03136/2003(H6N2)

$$
\begin{gathered}
\text { A/chicken/Germany/R28/03(H7N7) } \\
\text { A/turkey/Italy/472/99(H7N1) } \\
\text { A/mallard/Italy/299/05(H7N7) } \\
\text { A/duck/Jiangxi/1760/03(H7N7) }
\end{gathered}
$$

A/rhea/North Carolina/39482/1993(H7N1)

A/turkey/Germany/R33/96(H9N2)

A/duck/Jiangxi/1588/00(H7N7)

$\begin{array}{cccccc}98 & 153 & 183 & 195 & 226 & 228 \\ \text { Y } & \text { W } & \text { H } & \text { Y } & \text { Q } & \text { G } \\ \text { Y } & \text { W } & \text { H } & \text { Y } & \text { Q } & \text { G } \\ \text { Y } & \text { W } & \text { H } & \text { Y } & \text { Q } & \text { G } \\ \text { Y } & \text { W } & \text { H } & \text { Y } & \text { Q } & \text { G } \\ \text { Y } & \text { W } & \text { H } & \text { Y } & \text { Q } & \text { G }\end{array}$

$\begin{array}{llll}\text { Y } & \text { W } & \mathrm{H} & \mathrm{Y}\end{array}$

$\begin{array}{llll}\text { Y } & \text { W } & \text { H } & \text { Y }\end{array}$

$\begin{array}{llll}\mathrm{Y} & \mathrm{W} & \mathrm{H} & \mathrm{Y}\end{array}$

$\begin{array}{llll}\text { Y } & \text { W } & \mathrm{H} & \mathrm{Y}\end{array}$

$\begin{array}{llll}\text { Y } & \text { W } & \text { H } & \text { Y }\end{array}$

$\begin{array}{ll}\text { L } & \text { R } \\ \text { L } & \text { S } \\ \text { L } & \text { S } \\ \text { Q } & \text { G } \\ \text { Q } & \text { G }\end{array}$$$
Y
$$$$
\text { Y }
$$$$
\text { W } \quad \mathrm{H} \quad \mathrm{Y}
$$$$
\text { Q G }
$$$$
\text { Q G }
$$$$
\text { I S }
$$$$
\mathrm{Y}
$$

Y

Y

$\begin{array}{cccccc}\text { Y } & \text { W } & \text { H } & \text { Y } & \text { Q } & \text { G } \\ \text { Y } & \text { W } & \text { H } & \text { Y } & \text { Q } & \text { G } \\ \text { Y } & \text { W } & \text { H } & \text { Y } & \text { Q } & \text { G } \\ \text { Y } & \text { W } & \text { H } & \text { Y } & \text { Q } & \text { G }\end{array}$

$\begin{array}{llll}\text { Y } & \text { W } & \mathrm{H} & \mathrm{Y}\end{array}$

$\begin{array}{llll}\text { Y } & \text { W } & \text { H } & \text { Y }\end{array}$

$\begin{array}{llll}\text { Y } & \text { W } & \text { H } & \text { Y }\end{array}$

$\begin{array}{llll}\text { Y } & \text { W } & \text { H } & \text { Y }\end{array}$

$\begin{array}{llll}\text { Y } & \text { W } & \text { H } & \text { Y }\end{array}$

Q G

Q G

Q G

Q G

Q G

$\begin{array}{lllllll}Y & \text { W } & \text { H } & \text { Y } & \text { Q } & \text { G }\end{array}$

$\begin{array}{llllllll}Y & W & H & \text { Y } & \text { Q } & \text { G }\end{array}$

$\begin{array}{lllllll}Y & W & H & Y & Q & G\end{array}$

$\begin{array}{llllllll}Y & \text { W } & \text { H } & \text { Y } & \text { Q } & \text { G }\end{array}$

$\begin{array}{llllllll}\text { Y } & \text { W } & \text { H } & \text { Y } & \text { Q } & \text { G }\end{array}$

$\begin{array}{lllllll}\text { Y } & \text { W } & \text { H } & \text { Y } & \text { Q } & \text { G }\end{array}$

$\begin{array}{llllllll}\text { Y } & \text { W } & \text { H } & \text { Y } & \text { Q } & \text { G }\end{array}$ 


H9-chicken
H9-swine
H9-shovele
H10-mink
H10-chicke
H10-duck
H11-mallar
H11-chicke
H11-teal
H11-duck
H11-ruddy

H13-gull01

H13-gull02

H13-duck

H13-whale

H14-mallar

H15-shearw

H15-duck

H16-gull
A/chicken/Shandong/1/02(H9N2)

A/swine/Hong Kong/9/98-MA(H9N2)

A/shoveler/Iran/G54/03(H9)

A/mink/Sweden/1984(H10N4)

A/chick/ Germany/N/49 (H10N7)

A/Duck/Indonesia/Jakarta Utara1631-29/06(H10)

A/mallard/MN/346246/2000(H11N9)

A/chicken/NJ/4236-18/1998(H11N3)

A/green-winged teal/LA/9GW/1987(H11N9)

A/duck/546/1974(H11N9)

A/ruddy turnstone/NJ/650678/2002(H11N4)

A/gull/Maryland/704/1977(H13N6)

A/gull/Astrakhan/227/1984(H13N6)

A/duck/Siberia/272PF/1998(H13N6)

A/whale/Maine/328/1984(H13N2)

A/mallard/Astrakhan(Gurjev)/263/1982(H14N5)

A/shearwater/West Australia/2576/79(H15N9)

A/duck/Australia/341/83(H15N8)

A/black-headed gull/Sweden/5/99(H16N3)
Y

W

H Y

Q $\quad$ G

Y W

H $\quad \mathrm{Y}$

L $\quad G$

Y

W

$\mathrm{H}$

$\mathrm{Y}$

L $\quad G$

$\begin{array}{cccccc}\text { Y } & \text { W } & \text { H } & \text { Y } & \text { Q } & \text { G } \\ \text { Y } & \text { W } & \text { H } & \text { Y } & \text { Q } & \text { G } \\ \text { Y } & \text { W } & \text { H } & \text { Y } & \text { Q } & \text { G }\end{array}$

Y

Y

$\mathrm{Y}$

Y

$\mathrm{Y}$

$\mathrm{Y} \quad \mathrm{W}-\mathrm{H}$

$\begin{array}{ll}\mathrm{Y} & \mathrm{W} \\ \mathrm{Y} & \mathrm{W}\end{array}$

$\begin{array}{llllll}\text { Y } & \text { W } & \text { H } & \text { Y } & \text { Q } & \text { S }\end{array}$

$\begin{array}{lllllll}\text { Y } & \text { W } & \text { H } & \text { Y } & \text { Q } & \text { S }\end{array}$

$\begin{array}{lllllll}\text { Y } & \text { W } & \text { H } & \text { Y } & \text { Q } & \text { G }\end{array}$

$\begin{array}{llllll}\text { Y } & \text { W } & \text { H } & \text { Y } & \text { Q } & \text { G }\end{array}$

$\begin{array}{lllllll}\text { Y } & \text { W } & \text { H } & \text { Y } & \text { Q } & \text { G }\end{array}$

$\begin{array}{lllllll}\text { F } & \text { W } & \text { H } & \text { Y } & \text { Q } & \text { S }\end{array}$
Residues 226 and 228 have a certain significance for the recognition of a particular glycoside binding to its receptor. The $\alpha(2-3)$-glycoside receptor is recognized by hemagglutinin, which has a glutamine residue at position $226\left(\mathrm{Gln}^{226}\right)$, and a glycine residue at position 228 $\left(G \mid y^{228}\right)$ (Figure 25). The change of these residues for Leu $^{226}$ and Ser ${ }^{228}$ causes a specificity change and a change in the ability to recognize the $\alpha(2-6)$-glycoside receptor, which is characteristic for the viruses, which infect people. It is suspected that the difference in the receptor recognition is connected with hydrogen reactions and Van der Walls forces, which change depending on the different amino acid residues, at positions 226 and 228. Glutamine has a hydrophilic characteristic, while leucine has a hydrophobic character. Glycine and serine, on the other hand, have a similar characteristic identified as neutral-hydrophilic (Vines et al., 1998). Change of a single residue causes a change in the characteristic of a particular area from hydrophilic to hydrophilic-hydrophobic.

It is suspected that amino acid residue 190 (Figure 25) may affect the degree and the specificity of the receptor's bindings. A single Glu ${ }^{190} \rightarrow$ Asp $^{190}$ mutation can be the reason why the virus adapts and acquires the ability to bind both receptor types (Stevens, 2004). This type of a change is generated through a spot mutation of the third nucleotide.

As it was mentioned before, the strength of the binding is affected by the acquisition or loss of glycosylation site. The appearance of the asparagine residue (the glycosylation site) within the RBP impedes the access to the receptor, and thus decreases the infectiveness of the virus. There is an opposite situation if a strain loses its glycosylation site. Then, it becomes more pathogenic (Marinina et al., 2003). 


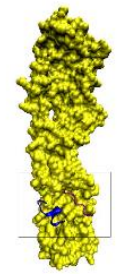

(a)

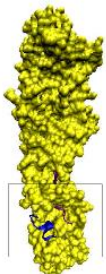

(c)
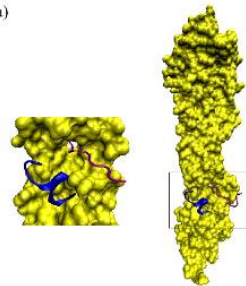

(b)
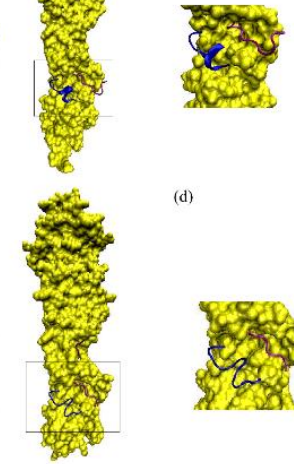

(d)
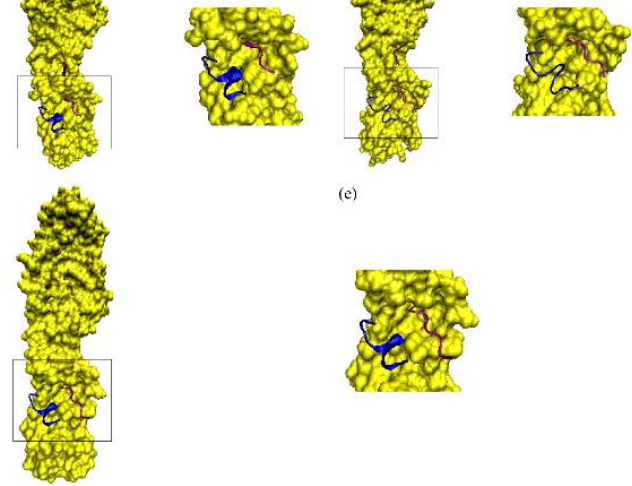

(e)

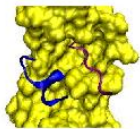

Figure 12. Crystallographic structures of haemagglutinins: a piece of HA1 subunit has been marked in purple and HA2 in blue, in the area of the site, where the HAO precursor's cut occurred. (a) H1 (PDB: 1rd8); (b) H3 (PDB: 2hmg); (c) H5 (PDB: 1jsm); (d) H7 (PDB: 1ti8); (e) H9 (PDB: 1jsd).

The structures of the receptor's binding site have been presented in Figure 15. It is noticeable that the site of sialic acid's binding creates a characteristic pocket, in which there are the maintained amino acid residues, which participate in stabilizing of this binding by creating hydrophobic reactions. The general topology of the "pocket" is similar in all the hemagglutinin types. However, H9 differs slightly from this principle, by creating a more open space. It is definitely affected by the improved access to the binding site, and this makes it easier to identify the virus.

In table 3 and 4, the comparison of significant, maintained fragments of the sialic receptor's binding site has been presented. Changes in positions 226 and 228 can be noticed, depending on the type of the virus.

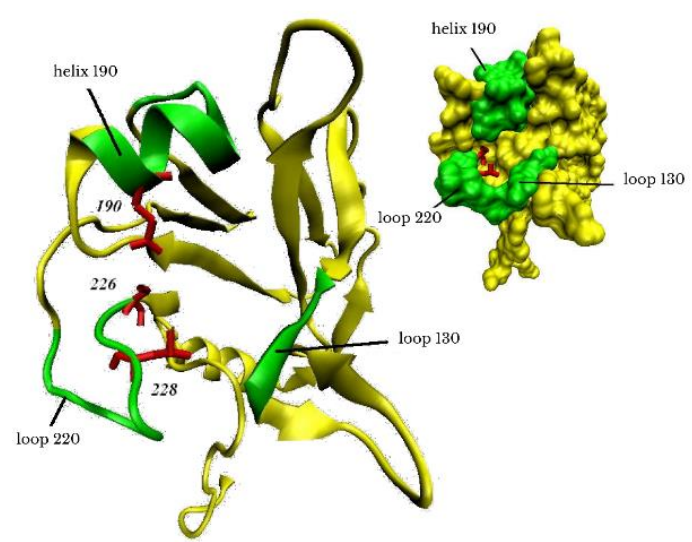

Figure 13. The receptor's binding site (PDB: 2hmg).

\section{Conclusions and discussion}

The influenza A virus may acquire pathogenicity in several ways. By increasing the amount of arginine residues and acquiring a $-\mathrm{R}-\mathrm{X}-\mathrm{R} / \mathrm{K}-\mathrm{R}-$ cassette within the site of the cut of the hemagglutinin precursor. By obtaining the ability to bind both types of the sialic receptors: $\alpha(2-3)$ - and $\alpha(2-6)$-glycoside, virus decreases the specificity and increases the hosts range in which it is able to multiply. Acquiring the pathogenicity is also possible via mutation of particular amino acid residues within the receptor's binding.

Increase in the number of arginine residues and obtaining the $-\mathrm{R}-\mathrm{X}-\mathrm{R} / \mathrm{K}-\mathrm{R}$ - cassette within the cut site may occur via a mutation. Certainly, every variation is possible, however, adaptations which would occur via spot mutations seem most probable.

When analyzing the nucleotide sequence of particular types of hemagglutinins, one may notice the mutation potential from serine into arginine $(S \rightarrow R: A G U \rightarrow A G A$ or AGG)

in haemagglutinin $\mathrm{H} 9$ (Table 4 pos. 35-37). There is an analogous situation in the case of threonine $(T \rightarrow R$ : ACA AGA) mutation in hemagglutinin $\mathrm{H} 6$ and $\mathrm{H} 11$ (Table 4 pos. 23,24, 41-44). Mutations of glutamine into lysine $(\mathrm{Q} \rightarrow \mathrm{K}: \mathrm{CAA}$ or $\mathrm{CAG} \rightarrow \mathrm{AAA}$ or $\mathrm{AAG})$ are possible in practically any type of hemagglutinins, in which the amino acid occurs - $\mathrm{H} 1, \mathrm{H} 2, \mathrm{H} 3, \mathrm{H} 6, \mathrm{H} 10, \mathrm{H} 14$. Mutations of all glutamine acids in $\mathrm{H} 2, \mathrm{H} 3, \mathrm{H} 4, \mathrm{H} 6, \mathrm{H} 7$, $\mathrm{H} 10$ and $\mathrm{H} 15$ (E $\rightarrow \mathrm{K}:$ GAA or GAG $\rightarrow$ AAA or AAG) can similarly lead to its replacement with lysine. 


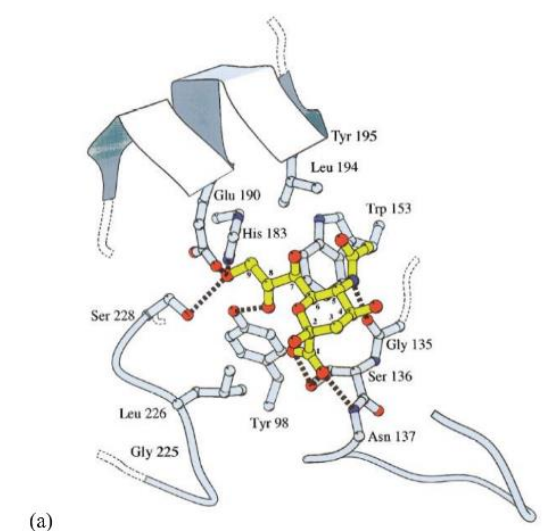

(a)

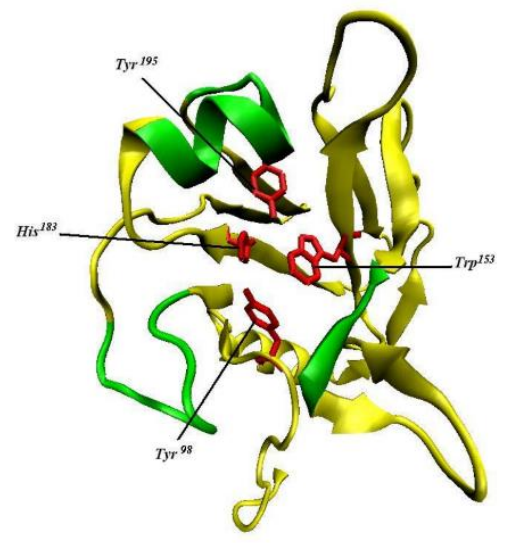

(b)

Figure 14. The receptor's binding site - maintained $\operatorname{Tyr}^{98}$, $\operatorname{Trp}^{153}$, His ${ }^{183}$, Tyr $^{195}$ amino acid residues: (a) the receptor's sialic acid has been marked in yellow (Martín et al., 1998), (b) (PDB: 2hmg).

The acquisition of another receptor also happens via the following mutations: Q226L (CAA or CAG $\rightarrow$ CUA or CUG) and G228S (GGU or GGC $\rightarrow$ AGU or AGC). The occurrence of both mutations at the same time is the condition for receiving the capacity of the $\alpha(2-6)$ glycoside receptor's binding (Vines et al., 1998). However, the amino acid sequence analysis shows that some non-pathogenic $\mathrm{H} 9, \mathrm{H} 13$ and $\mathrm{H} 16$ strains have acquired the mutation in one of the positions (Table 4 pos. 36-37, 46-49, 53) and they are potential future pathogens. As it has already been mentioned, a virus may also adapt to infect the host's cells, by mutating single amino acid residues. Residue 190 and its D190E mutation is a good example because it results in the ability to bind both types of receptors. To sum up the discussion on the hemagglutinins' structures, we need to emphasize the fact that the spatial structures of most hemagglutinins are similar. H9 is an exception, which is slightly different from the others and as it was mentioned before, its adaptation mechanism will probably take a different course, then in the cases of the $\mathrm{H} 1, \mathrm{H} 2, \mathrm{H} 3 \mathrm{H} 5$ or $\mathrm{H} 7$ strains.
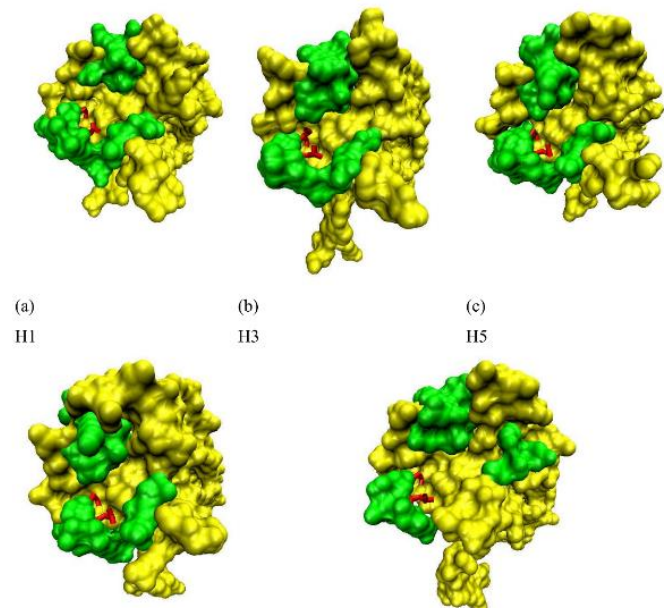

(b)

(c)

H3

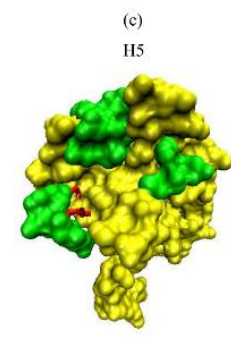

(d)

(e)

H7

H

Figure 15. Crystallographic structures of the haemagglutinin binding site. (a) H1 (PDB: 1rd8); (b) H3 (PDB: 2hmg); (c) H5 (PDB: 1jsm); (d) H7 (PDB: 1ti8); (e) H9 (PDB: 1jsh).

If we analyze the amino acid structure and sequence, we can notice a large $\mathrm{H} 9$ hemagglutinin potential to acquire various pathogenicity features. Some strains (A/swine/Hong Kong/9/98-MA(H9N2) as well as A/Shoveler/Iran/G54/03(H9)) have already got the mutations at the receptor binding site and may soon acquire the ability to infect human cells. At the same time, these strains have the potential to mutate within the site of the cut and thus increase the already doubled number of arginines in the area, which makes the pathogen more dangerous. It seems to be a mere question of time before the $\mathrm{H} 9$ type virus becomes another threat to the world. However, one cannot forget about other, theoretically benign strains like $\mathrm{H} 6, \mathrm{H} 11$, $\mathrm{H} 16$, or especially $\mathrm{H} 13$, which can mutate slowly but regularly, throughout their phase of slumber.

\section{References}

Brändén, C., \& Tooze, J. (1991). Introduction to protein structure. Second Edition. Garland Publishing.

de Jong, M. D., \& Hien, T. T. (2006). Avian influenza A (H5N1). Journal of Clinical Virology: The Official Publication of the Pan American Society for Clinical Virology, 35(1), 2-13. https://doi.org/10.1016/j.jcv.2005.09.002

Garten, R. J., Lai, S., Zhang, J., Liu, W., Chen, J., Vlahov, D., \& Yu, X. F. (2004). Rapid transmission of hepatitis $C$ virus among young injecting heroin users in Southern China. International Journal of Epidemiology, 
33(1), 182-188. https://doi.org/10.1093/ije/dyh019

Ilyushina, N. A., Rudneva, I. A., Gambaryan, A. S., Tuzikov, A. B., \& Bovin, N. V. (2004). Receptor specificity of $\mathrm{H} 5$ influenza virus escape mutants. Virus Research, 100(2), 237-241. https://doi.org/10.1016/j.virusres.2003.12.032

Kaverin, N. V, Rudneva, I. A., llyushina, N. A., Lipatov, A. S., Varich, N. L., \& Webster, R. G. (2004). Differences and similarities in the structure of the antigenic epitopes on influenza A virus hemagglutinin molecule of different subtypes. International Congress Series, 1263(C), 682686. https://doi.org/10.1016/j.ics.2004.02.157

Klenk, H. D., Wagner, R., Heuer, D., \& Wolff, T. (2002). Importance of hemagglutinin glycosylation for the biological functions of influenza virus. Virus Research, 82(1-2), 73-75. https://doi.org/10.1016/S01681702(01)00389-6

Kogure, T., Suzuki, T., Takahashi, T., Miyamoto, D., Hidari, K. I. P. J., Guo, C.-T., ... Suzuki, Y. (2006). Human trachea primary epithelial cells express both sialyl(a2-3)Gal receptor for human parainfluenza virus type 1 and avian influenza viruses, and sialyl(a2-6)Gal receptor for human influenza viruses. Glycoconjugate Journal, 23(1-2), 101-106. https://doi.org/10.1007/s10719-006-5442-z

Kováčová, A., Ruttkay-Nedecký, G., Haverlík, I. K., \& Janeček, S. (2002). Sequence similarities and evolutionary relationships of influenza virus A hemagglutinins. Virus Genes, 24(1), 57-63. https://doi.org/10.1023/A:1014038120979

Lai, A. L., \& Tamm, L. K. (2007). Locking the kink in the influenza hemagglutinin fusion domain structure. Journal of Biological Chemistry, 282(33), 23946-23956. https://doi.org/10.1074/jbc.M704008200

Marinina, V. P., Gambaryan, A. S., Bovin, N. V., Tuzikov, A. B., Shilov, A. A., Sinitsyn, B. V., \& Matrosovich, M. N. (2003). The Effect of Losing Glycosylation Sites Near the Receptor-Binding Region on the Receptor Phenotype of the Human Influenza Virus H1N1. Molecular Biology, 37(3), 468-472. https://doi.org/10.1023/A:1024207931650

Martín, J., Wharton, S. A., Lin, Y. P., Takemoto, D. K., Skehel, J. J., Wiley, D. C., \& Steinhauer, D. A. (1998). Studies of the binding properties of influenza hemagglutinin receptor- site mutants. Virology, 241(1), 101-111. https://doi.org/10.1006/viro.1997.8958

Mazur, E., \& Marcey, D. (2011). Influenza Hemagglutinin. Retrieved June 8, 2018, from
https://earth.callutheran.edu/Academic_Programs/Dep artments/BioDev/omm/jsmolnew/ha/ha.html

Nakamura, K., Sugawara, K., Tsuchiya, E., Hongo, S., Matsuzaki, Y., Li, Z.-N., \& Muraki, Y. (2002). Effect of addition of new oligosaccharide chains to the globular head of influenza A/H2N2 virus haemagglutinin on the intracellular transport and biological activities of the molecule. Journal of General Virology, 83(5), 11371146. https://doi.org/10.1099/0022-1317-83-5-1137

Nayak, D. P., Hui, E. K.-W., \& Barman, S. (2004). Assembly and budding of influenza virus. Virus Research, 106(2), 147-165. https://doi.org/10.1016/j.virusres.2004.08.012

Ohuchi, M., Ohuchi, R., Feldmann, A., \& Klenk, H.-D. (1997). Regulation of receptor binding affinity of influenza virus hemagglutinin by its carbohydrate moiety. Journal of Virology, 71(11), 8377-8384. Retrieved from http://www.ncbi.nlm.nih.gov/pubmed/9343193

Ohuchi, R., Ohuchi, M., Garten, W., \& Klenk, H. D. (1997). Oligosaccharides in the stem region maintain the influenza virus hemagglutinin in the metastable form required for fusion activity. Journal of Virology, 71(5), 3719-3725. Retrieved from http://www.ncbi.nlm.nih.gov/pubmed/9094646

Russell, R. J., Stevens, D. J., Haire, L. F., Gamblin, S. J., \& Skehel, J. J. (2006). Avian and human receptor binding by hemagglutinins of influenza $A$ viruses. Glycoconjugate Journal, 23(1-2), 85-92. https://doi.org/10.1007/s10719-006-5440-1

Stevens, J. (2004). Structure of the Uncleaved Human H1 Hemagglutinin from the Extinct 1918 Influenza Virus. Science, 303(5665), 1866-1870. https://doi.org/10.1126/science.1093373

Subbarao, K., Klimov, A., Katz, J., Regnery, H., Lim, W., Hall, H., ... Cox, N. (1998). Characterization of an Avian Influenza A (H5N1) Virus Isolated from a Child with a Fatal Respiratory Illness. Science, 279(5349), 393-396. https://doi.org/10.1126/science.279.5349.393

Vines, A., Wells, K., Matrosovich, M., Castrucci, M. R., Ito, T., \& Kawaoka, Y. (1998). The role of influenza A virus hemagglutinin residues 226 and 228 in receptor specificity and host range restriction. Journal of Virology, 72(9), 7626-7631. Retrieved from http://www.ncbi.nlm.nih.gov/pubmed/9696865

Wagner, R., Feldmann, A., Wolff, T., Pleschkab, S., Garten, W., \& Klenk, H. (2001). Hemagglutinin and neuraminidase as determinants of influenza virus 
pathogenicity. In nternational Congress Series (pp. 533543). Elsevier.

Webster, R. G. (2002). The importance of animal influenza for human disease. Vaccine, 20(SUPPL. 2), S16-S20. https://doi.org/10.1016/S0264$410 \times(02) 00123-8$

Wiley, D. C., Wilson, I. A., \& Skehel, J. J. (1981). Structural identification of the antibody-binding sites of Hong Kong influenza haemagglutinin and their involvement in antigenic variation. Nature, 289(5796), 373-378. https://doi.org/10.1038/289373a0

Zhirnov, O. P., Vorobjeva, I. V., Ovcharenko, A. V., \& Klenk, H. D. (2003). Intracellular cleavage of human influenza a virus hemagglutinin and its inhibition. Biochemistry. Biokhimiia, 68(9), 1020-1026. https://doi.org/10.1023/A:1026020831036 